\title{
A validation study of the Caregiver Mastery Scale for partners of patients with acquired brain injury
}

Citation for published version (APA):

Cox, V. C., Schepers, V. P., Ketelaar, M., Kruithof, W. J., van Heugten, C. M., \& Visser-Meily, J. M. (2018). A validation study of the Caregiver Mastery Scale for partners of patients with acquired brain injury. Clinical Rehabilitation, 32(4), 493-500. https://doi.org/10.1177/0269215517732821

Document status and date:

Published: 01/04/2018

DOI:

10.1177/0269215517732821

Document Version:

Publisher's PDF, also known as Version of record

Document license:

Taverne

Please check the document version of this publication:

- A submitted manuscript is the version of the article upon submission and before peer-review. There can be important differences between the submitted version and the official published version of record.

People interested in the research are advised to contact the author for the final version of the publication, or visit the DOI to the publisher's website.

- The final author version and the galley proof are versions of the publication after peer review.

- The final published version features the final layout of the paper including the volume, issue and page numbers.

Link to publication

\footnotetext{
General rights rights.

- You may freely distribute the URL identifying the publication in the public portal. please follow below link for the End User Agreement:

www.umlib.nl/taverne-license

Take down policy

If you believe that this document breaches copyright please contact us at:

repository@maastrichtuniversity.nl

providing details and we will investigate your claim.
}

Copyright and moral rights for the publications made accessible in the public portal are retained by the authors and/or other copyright owners and it is a condition of accessing publications that users recognise and abide by the legal requirements associated with these

- Users may download and print one copy of any publication from the public portal for the purpose of private study or research.

- You may not further distribute the material or use it for any profit-making activity or commercial gain

If the publication is distributed under the terms of Article $25 \mathrm{fa}$ of the Dutch Copyright Act, indicated by the "Taverne" license above, 


\title{
A validation study of the Caregiver Mastery Scale for partners of patients with acquired brain injury
}

Clinical Rehabilitation 2018, Vol. 32(4) 493-500 (C) The Author(s) 2017 Reprints and permissions: sagepub.co.uk/journalsPermissions.nav DOI: 10.1 177/026921551773282। journals.sagepub.com/home/cre @SAGE

\author{
Vincent CM Cox ${ }^{1,2}$, Vera PM Schepers ${ }^{1,2,3}$, \\ Marjolijn Ketelaar ${ }^{1,2}$, Willeke J Kruithof ${ }^{1,2,3}$, \\ Caroline M van Heugten ${ }^{4,5}$ \\ and Johanna MA Visser-Meily1,2,3
}

\begin{abstract}
Objective: To validate the Caregiver Mastery Scale for partners of patients with acquired brain injury. Design: The score distributions, internal consistency and convergent validity of the Caregiver Mastery Scale were determined.

Subjects: A total of 92 partners (53\% male, age 62 years) of patients with acquired brain injury ( $91 \%$ stroke) discharged from inpatient rehabilitation (time since injury 32 months).

Main measures: Outcome measure: Caregiver Mastery Scale. Reference measures: Caregiver Strain Index, Hospital Anxiety and Depression Scale and CarerQoL.

Results: The Caregiver Mastery Scale has a normal distribution, with no floor or ceiling effects. Its internal consistency is acceptable (Cronbach's alpha: 0.75 ). The convergent validity analyses confirmed our hypothesis that higher scores on the Caregiver Mastery Scale correlate with less burden, lower levels of anxiety and depression and greater well-being. Furthermore, partners scoring high on the Caregiver Mastery Scale mostly scored below the clinical cut-off scores on the Caregiver Strain Index and the anxiety and depression subscales of the Hospital Anxiety and Depression Scale, whereas partners scoring low on the Caregiver Mastery Scale were more likely to score above the cut-off points.

Conclusion: The Caregiver Mastery Scale is a valid instrument to assess the caregiver mastery of partners of patients with acquired brain injury.
\end{abstract}

\footnotetext{
'Center of Excellence in Rehabilitation Medicine, Brain Center Rudolf Magnus, University Medical Center Utrecht, Utrecht, The Netherlands

2De Hoogstraat Rehabilitation, Utrecht, The Netherlands ${ }^{3}$ Department of Rehabilitation, Physical Therapy Science \& Sports, Brain Center Rudolf Magnus, University Medical Center Utrecht, Utrecht, The Netherlands ${ }^{4}$ Department of Neuropsychology and Psychopharmacology, Faculty of Psychology and Neuroscience, Maastricht University, Maastricht, The Netherlands
}

\footnotetext{
${ }^{5}$ School for Mental Health and Neuroscience, Faculty of Health, Medicine and Life Sciences, Maastricht University Medical Center, Maastricht, The Netherlands

Corresponding author:

Vera PM Schepers, Center of Excellence in Rehabilitation Medicine, Brain Center Rudolf Magnus, University Medical Center Utrecht, Huispost W0I.I2I, PO Box 85500, 3508 GA Utrecht, The Netherlands. Email: V.P.M.Schepers-3@umcutrecht.nl
} 


\section{Keywords}

Caregiving, mastery, partners, acquired brain injury, validity

Received: 29 March 2017; accepted: 30 August 2017

\section{Introduction}

Nowadays, most people with acquired brain injury are discharged home where informal caregivers take care of them. The role of caregiving is often fulfilled by the partner, who is the most close to the patient, and may lead to negative consequences such as high levels of burden, ${ }^{1-5}$ anxiety $^{3,4}$ and depressive symptoms ${ }^{1-4,6}$ and poor well-being. ${ }^{1,4}$

Several psychological resources and coping responses can protect against the negative consequences of stressors such as caregiving. ${ }^{7}$ Mastery is considered to be one of these psychological resources and is defined as "the belief that one is able to influence or control life events and that one is competent or effective in managing those events in order to produce desired outcomes" (see ref. 8, p. 163).

In 1978, Pearlin and Schooler ${ }^{7}$ constructed a 7-item scale to assess mastery. Elaborating on this global mastery scale, Christensen et al. ${ }^{8}$ created four specific mastery scales for women in their roles as mother, wife, employee and caregiver for their own parent. They found mastery in the caregiving role to be positively related to well-being and negatively correlated with depressive symptoms. ${ }^{8}$ Little is known about the psychometric properties of this Caregiver Mastery Scale. The internal consistency and responsiveness have been investigated in a group of women taking care of their parent ${ }^{8}$ and caregivers of glioma patients, ${ }^{9}$ respectively. Whether the Caregiver Mastery Scale can be used to measure mastery in caregiving for other conditions, such as patients with acquired brain injury, is unknown. The aim of this study was therefore to determine the validity of the Caregiver Mastery Scale for partners of patients with acquired brain injury.

The objectives of this study were to (1) investigate the score distributions of the Caregiver Mastery Scale, (2) examine the internal consistency of the
Caregiver Mastery Scale and (3) test the convergent validity of the Caregiver Mastery Scale for partners of patients with acquired brain injury. The corresponding hypotheses were that higher scores on the Caregiver Mastery Scale would be related to (1) less burden, ${ }^{4}(2)$ less anxiety, ${ }^{4,10}(3)$ less depression ${ }^{4,8,10,11}$ and (4) greater well-being. 4,8

\section{Methods}

\section{Participants}

Participants in this cross-sectional study were the partners of patients with acquired brain injury discharged from inpatient rehabilitation at De Hoogstraat Rehabilitation(Utrecht, the Netherlands). Partners were invited when (1) the patient had a nonprogressive, non-neurodegenerative acquired brain injury; (2) the patient was admitted to the rehabilitation center between June 2013 and June 2015 and (3) the partner was at least 18 years old. Exclusion criteria were (1) the absence of Internet access and (2) insufficient command of the Dutch language.

\section{Procedure}

Letters signed by the attending physician were sent in April 2016 to inform the partners about the study and ask them to participate. Participants were invited to fill in on-line questionnaires, and the letter contained the URL and login credentials required to gain access. Reminder letters were sent after one month when partners had not responded to the first invitation. The participants consented to the use of their data for this study by logging in to the website. The medical ethics committee of The Hoogstraat approved the study and Good Clinical Practice Guidelines ${ }^{12}$ were followed. 


\section{Measures}

The demographic characteristics of the partner (e.g. age, gender, country of birth, educational level and employment), as well as the patient's diagnosis and the date of diagnosis, were selfreported by the partners.

The Caregiver Mastery Scale ${ }^{8}$ is a 7-item selfreport scale, indicating the extent to which respondents agree (5) or disagree (1) with each item. Three items with negative statements are reverse-scored. Total scores can range from 7 to 35 , with higher scores reflecting greater caregiver mastery. The Dutch version used in this study was obtained from the researchers who investigated mastery among caregivers of patients with high-grade glioma. ${ }^{9}$ The English and Dutch versions can be found in the Appendix.

The following measures were used to assess the convergent validity:

The Caregiver Strain Index ${ }^{13,14}$ consists of 13 items which can be scored as "yes" or "no," The total score ranges from 0 to 13 , with higher scores reflecting a higher caregiver burden. A score of 7 or higher is considered to indicate a substantial burden. The Caregiver Strain Index is the most commonly used scale to assess burden among caregivers of stroke patients ${ }^{15}$ and is recommended in the Dutch stroke care guidelines. ${ }^{16}$

The Carer $Q o L^{17,18}$ instrument determines the care-related quality of life of informal caregivers. It consists of the CarerQoL-7D and the CarerQoLVAS. The CarerQoL-7D uses 7 items to measure the subjective burden in various dimensions of the caregiving situation. Low scores indicate a high burden. The CarerQoL-VAS assesses the caregivers' well-being, with higher scores indicating greater well-being.

The Hospital Anxiety and Depression Scale ${ }^{19-21}$ consists of a 7-item anxiety and a 7-item depression subscale. Subscale total scores above 7 indicate an anxiety disorder or depression, respectively.

\section{Statistical analyses}

Data were analyzed using IBM SPSS Statistics version 22 for Windows. The score distribution of the Caregiver Mastery Scale was examined. Skewness was considered to be present if the skewness value was below -1.0 or above 1.0. A kurtosis value between -1.0 and 1.0 was considered acceptable. Floor and ceiling effects were considered to be present if at least $15 \%$ of the participants achieved the worst or best score, respectively. ${ }^{22}$

To determine internal consistency, Cronbach's alpha and item-total correlation were calculated. Internal consistency was considered acceptable if Cronbach's alpha was between 0.70 and $0.90 .{ }^{23} \mathrm{~A}$ corrected item-total correlation value below 0.3 indicates that the corresponding item does not correlate very well with the scale overall and may be dropped. ${ }^{23}$

The convergent validity of the Caregiver Mastery Scale was examined by investigating the correlations between the Caregiver Mastery Scale and the other measures. Since the Caregiver Mastery Scale is an ordinal scale, the Spearman rank-order correlation coefficient was used. Convergent validity was considered to be good if the correlation coefficient was greater than 0.6 , moderate if the coefficient was between 0.3 and 0.6 , and poor if the coefficient was below $0.3 .{ }^{15}$ Moderate correlations were expected, since the instruments measure concepts that are related, but not identical, to caregiver mastery. If at least 3 out of 4 hypotheses were confirmed, the Caregiver Mastery Scale was considered to have convergent validity. ${ }^{22}$

Elaborating on the convergent validity, we investigated the relationship between Caregiver Mastery Scale scores and the burden, anxiety and depression outcomes with respect to their clinical cut-off scores. Two subgroups were created, consisting of the $25 \%$ of partners with lowest scores and the $25 \%$ with the highest scores on the Caregiver Mastery Scale. For both groups, the percentage of respondents scoring below and above the clinical cut-off scores of the Caregiver Strain Index and the anxiety and depression subscales of the Hospital Anxiety and Depression Scale were determined. 
Table I. Acquired brain injury characteristics of the patients and demographics of their partners $(n=92)$.

\begin{tabular}{lc}
\hline Patient characteristics & \\
\hline Diagnosis of patient, $n(\%)$ & \\
Ischemic stroke & $62(67.4)$ \\
Hemorrhagic stroke & $22(23.9)$ \\
Traumatic brain injury & $4(4.3)$ \\
Other & $4(4.3)$ \\
Time since diagnosis in months, & $32(21)$ \\
median (IQR) & \\
\hline
\end{tabular}

\begin{tabular}{lc}
\hline Partner characteristics & \\
\hline $\begin{array}{l}\text { Age (years), mean (SD) } \\
\text { Gender, } n(\%)\end{array}$ & $62.4(10.2)$ \\
$\quad$ Male & $49(53.3)$ \\
$\quad$ Female & $43(46.7)$ \\
$\begin{array}{l}\text { Country of birth, } n(\%) \\
\quad \text { The Netherlands }\end{array}$ & $88(95.7)$ \\
$\quad$ Other & $4(4.3)$ \\
Educational level, $n(\%)$ & \\
$\quad$ High & $37(40.2)$ \\
$\quad$ Medium & $20(21.7)$ \\
$\quad$ Low & $35(38.0)$ \\
Employed, $n(\%)$ & \\
$\quad$ Full-time ( $\geq 32$ hours per week) & $25(27.2)$ \\
$\quad$ Part-time (<32 hours per week) & $22(23.9)$ \\
$\quad$ Unemployed & $45(48.9)$ \\
\hline
\end{tabular}

$n$, number; IQR, interquartile range; SD, standard deviation.

\section{Results}

A total of 255 partners were invited to participate, 95 of whom (37\%) logged in to the on-line questionnaire. Three persons only answered a few demographic questions but quit before filling in the Caregiver Mastery Scale and were therefore excluded from the analyses. Hence, the study sample consisted of 92 partners. The age of the respondents and the patients' diagnosis in our study sample are similar to those of the invited population. Men were more likely to respond: 49 out of $92(53 \%)$ of the study sample were male, compared with 111 out of 255 (44\%) in the invited population.

Table 1 presents the acquired brain injury characteristics of the patients and the demographic characteristics of their partners.
Table 2. Descriptive statistics of the Caregiver Mastery Scale $(n=92)$.

\begin{tabular}{lc}
\hline & $\begin{array}{c}\text { Caregiver Mastery } \\
\text { Scale (range: 7-35) }\end{array}$ \\
\hline Minimum & 13 \\
Maximum & 34 \\
Mean (SD) & $23.63(4.29)$ \\
Median (IQR) & $24(5)$ \\
Skewness (SE) & $-0.45(0.3)$ \\
Kurtosis (SE) & $0.33(0.5)$ \\
\hline
\end{tabular}

SD, standard deviation; IQR, interquartile range; $S E$, standard error.

\section{Score distributions}

Table 2 presents the descriptive statistics of the Caregiver Mastery Scale for 92 partners of patients with acquired brain injury. No floor or ceiling effects were found and the skewness and kurtosis values showed a normal distribution of the Caregiver Mastery Scale.

\section{Internal consistency}

The Caregiver Mastery Scale showed acceptable internal consistency, with a Cronbach's alpha value of 0.75 . The item-total correlations are presented in Table 3. Item 5 showed an unacceptable item-total correlation. Removing this item from the scale, however, would only slightly improve the internal consistency.

\section{Convergent validity}

The results of the convergent validity analyses are shown in Table 4. Higher scores on the Caregiver Mastery Scale correlate with less burden, lower levels of anxiety and depression and greater wellbeing. All tested relations showed a moderate correlation.

The correlations of the Caregiver Mastery Scale with the CarerQoL-7D and the subscales of the Hospital Anxiety and Depression Scale were determined for a sample of 90 partners, because two respondents had missing data on these measures. The correlation of the Caregiver Mastery Scale 
Table 3. Item-total correlations of the Dutch version of the Caregiver Mastery Scale $(n=92)$.

\begin{tabular}{|c|c|c|c|}
\hline & & $\begin{array}{l}\text { Corrected item-total } \\
\text { correlation }\end{array}$ & $\begin{array}{l}\text { Cronbach's alpha } \\
\text { if item deleted }\end{array}$ \\
\hline Item I & $\begin{array}{l}\text { You are usually certain about what to do in } \\
\text { caring for your partner }\end{array}$ & 0.42 & 0.73 \\
\hline Item 2 & $\begin{array}{l}\text { No matter what you do as a caregiver, it never } \\
\text { seems to be enough }\end{array}$ & 0.45 & 0.73 \\
\hline Item 3 & $\begin{array}{l}\text { In general, you are able to handle most } \\
\text { problems in the care of your partner }\end{array}$ & 0.57 & 0.70 \\
\hline Item 4 & $\begin{array}{l}\text { You are not doing as well as you would like as } \\
\text { a caregiver }\end{array}$ & 0.42 & 0.73 \\
\hline Item 5 & $\begin{array}{l}\text { You feel that you have a great deal of influence } \\
\text { over the things that happen in caregiving }\end{array}$ & 0.27 & 0.76 \\
\hline Item 6 & $\begin{array}{l}\text { You believe you are mastering most of the } \\
\text { challenges in caregiving }\end{array}$ & 0.70 & 0.67 \\
\hline Item 7 & $\begin{array}{l}\text { You have lost some control of your life since } \\
\text { your partner's illness }\end{array}$ & 0.47 & 0.72 \\
\hline
\end{tabular}

Table 4. Correlations between the Caregiver Mastery Scale and the other measures.

\begin{tabular}{|c|c|c|c|c|c|}
\hline & \multicolumn{2}{|l|}{ Burden } & \multirow{2}{*}{$\begin{array}{l}\text { Anxiety } \\
\text { HADS-A } \\
(n=90)\end{array}$} & \multirow{2}{*}{$\begin{array}{l}\text { Depression } \\
\text { HADS-D } \\
(n=90)\end{array}$} & \multirow{2}{*}{$\begin{array}{l}\text { Well-being } \\
\text { CarerQoL-VAS } \\
(n=68)\end{array}$} \\
\hline & $\operatorname{CSI}(n=92)$ & $\begin{array}{l}\text { CarerQoL-7Da } \\
(n=90)\end{array}$ & & & \\
\hline Caregiver Mastery Scale & $-0.58 * *$ & $0.46 * *$ & $-0.45^{* *}$ & $-0.55^{* *}$ & $0.57 * *$ \\
\hline
\end{tabular}

CSI, Caregiver Strain Index; CarerQoL-7D, care-related quality of life-seven dimensions of burden; HADS-A, Hospital Anxiety and Depression Scale-Anxiety subscale; HADS-D, Hospital Anxiety and Depression Scale_Depression subscale; CarerQoLVAS, care-related quality of life-visual analog scale for well-being.

Spearman's rank correlation coefficients.

aLow scores indicate a high burden and reflect a poor care-related quality of life.

$* * P<0.0$ I (two-tailed).

Table 5. Subgroup analyses of the Caregiver Mastery Scale relative to clinical cut-off scores.

\begin{tabular}{|c|c|c|c|c|c|c|}
\hline & \multicolumn{2}{|l|}{ Burden } & \multicolumn{2}{|l|}{ Anxiety } & \multicolumn{2}{|l|}{ Depression } \\
\hline & $\begin{array}{l}\text { Below } \\
\text { CSI }<7\end{array}$ & $\begin{array}{l}\text { Above } \\
\mathrm{CSI} \geq 7\end{array}$ & $\begin{array}{l}\text { Below } \\
\text { HADS-A } \leq 7\end{array}$ & $\begin{array}{l}\text { Above } \\
\text { HADS-A >7 }\end{array}$ & $\begin{array}{l}\text { Below } \\
\text { HADS-D } \leq 7\end{array}$ & $\begin{array}{l}\text { Above } \\
\text { HADS-D }>7\end{array}$ \\
\hline $25 \%$ lowest CMS scores & $13.0 \%$ & $87.0 \%$ & $56.5 \%$ & $43.5 \%$ & $47.8 \%$ & $52.2 \%$ \\
\hline $25 \%$ highest CMS scores & $86.4 \%$ & $13.6 \%$ & $86.4 \%$ & $13.6 \%$ & $95.5 \%$ & $4.5 \%$ \\
\hline
\end{tabular}

CMS, Caregiver Mastery Scale; CSI, Caregiver Strain Index; HADS-A, Hospital Anxiety and Depression Scale-Anxiety subscale; HADS-D, Hospital Anxiety and Depression Scale-Depression subscale.

with the CarerQoL-VAS was tested for 68 respondents, due to missing data in 24 cases.

The percentages of respondents scoring below and above the clinical cut-off scores for burden, anxiety and depression are displayed in Table 5. Most partners scoring high on the Caregiver Mastery Scale scored below the clinical cut-off scores on the Caregiver Strain Index and the 
anxiety and depression subscales of the Hospital Anxiety and Depression Scale. Partners scoring low on the Caregiver Mastery Scale were more likely to score above the cut-off points.

\section{Discussion}

The Caregiver Mastery Scale proved to be a valid instrument for partners of patients with acquired brain injury. In our study sample, the Caregiver Mastery Scale had a normal distribution, with no floor or ceiling effects. This means that the instrument can identify persons with extremely low or extremely high caregiver mastery. Our findings for partners of patients with acquired brain injury are in accordance with those in the study by Christensen et al., ${ }^{8}$ who reported a similar range, mean and standard deviation among women caring for their impaired parent.

The internal consistency of the Caregiver Mastery Scale is acceptable. The Cronbach's alpha found in this study is comparable to what Christensen et al. ${ }^{8}$ found $(0.75 \mathrm{vs} .0 .68)$. In spite of the acceptable internal consistency, item 5 does not fit the scale very well. Careful analysis of this item has led to the conclusion that there may have been an incorrect translation from English to Dutch. The Dutch statement seems to concern all the care for the patient and could be interpreted to include care provided by health professionals and not merely informal caregiving. We suggest not to remove the item from the scale, as it provides useful information to indicate where the problems are experienced and enables support for the caregiver to be more targeted. Furthermore, deletion of the item hardly increases the internal consistency. Consequently, we recommend adjusting the Dutch item to make it more in accordance with the original English item. The suggested adjusted version of item 5 can be found in the Appendix.

All hypotheses regarding the correlations between the Caregiver Mastery Scale and the other concepts were confirmed, proving convergent validity. Higher scores on the Caregiver Mastery Scale are related with less burden, less anxiety, less depression and greater well-being. As expected, the relations we tested showed a moderate correlation, since the concepts are related, but not identical, to mastery. As shown in Table 5, most partners scoring high on the Caregiver Mastery Scale scored below the clinical cut-off scores for burden, anxiety and depression, whereas the partners scoring low on the Caregiver Mastery Scale were more likely to score above the clinical cut-off scores. These findings support the clinical relevance of measuring caregiver mastery.

Our study design did not allow having missing items within a scale, as the measurements were conducted via a web-based application. However, two respondents quit before filling in all the pages, resulting in entire instruments being missed. Also, the visual analog scale (CarerQoL-VAS) was not visible for all respondents due to unforeseen technical issues, resulting in missing data. The missing data resulted in smaller but still acceptable sample sizes for the convergent validity analyses. It did not affect the analyses for score distribution and internal consistency of the Caregiver Mastery Scale.

The results of this study are limited to the partners who chose to participate and might not be applicable for the ones who did not respond. We do not know whether they score differently on caregiver mastery. The patients' diagnosis and age of the partners in the study sample are, however, comparable with the invited population, but fewer women responded.

Furthermore, we excluded partners without Internet access, as the questionnaires were delivered on-line. The results should, therefore, be interpreted with caution for partners without Internet access, who are most likely older of age, lower educated and woman. ${ }^{24}$

The sample in this study was a large group of partners of patients with acquired brain injury who had been discharged from inpatient rehabilitation. Our results demonstrate that the Caregiver Mastery Scale is a valid instrument for this population. The generalizability of these findings to all caregivers may be limited. Results may differ for partners of patients with acquired brain injury who are not admitted to inpatient rehabilitation, for informal caregivers who are not the partner of the care receiver and for informal caregivers of other categories of patients. The validity of the Caregiver Mastery Scale for other informal caregivers, therefore, requires further research. 
Negative caregiving consequences, such as burden and emotional problems, have been widely investigated. Positive aspects of caregiving have received less attention, although they are important since they can buffer the negative consequences. ${ }^{25}$ Caregiving mastery is one of these positive aspects which may protect against the negative consequences of caregiving, ${ }^{7}$ and assessing caregivers' mastery could provide greater insight into the caregiving situation. Additionally, interventions aimed at improving caregiver mastery should be developed in order to achieve better psychological well-being among caregivers. ${ }^{26}$ The effect of these interventions can be determined with the Caregiver Mastery Scale, which is able to measure change in caregiving mastery. ${ }^{9}$ Interventions are particularly relevant for partners of patients with acquired brain injury, a growing group experiencing numerous negative consequences of caregiving. Our study shows that the Caregiver Mastery Scale is a valid instrument to assess caregiver mastery in this population.

\section{Clinical Messages}

- The Caregiver Mastery Scale is a valid instrument for partners of patients with acquired brain injury.

- Higher caregiver mastery is related to less burden, less anxiety and less depression symptoms.

\section{Acknowledgements}

The authors would like to thank all the partners for participating in the study, their colleagues from De Hoogstraat Rehabilitation for assisting with recruitment and Melissa Bravenboer De Sousa for her assistance in conducting the study.

\section{Declaration of conflicting of interests}

The author(s) declared no potential conflicts of interest with respect to the research, authorship and/or publication of this article.

\section{Funding}

The author(s) disclosed receipt of the following financial support for the research, authorship and/or publication of this article: This study was financially supported by FNO, Revalidatie Nederland and the Netherlands Organisation for Health Research and Development (ZonMw; grant number 630000002).

\section{References}

1. Visser-Meily A, Post M, Schepers V, et al. Spouses' quality of life 1 year after stroke: prediction at the start of clinical rehabilitation. Cerebrovasc Dis 2005; 20: 443-448.

2. Kruithof WJ, Post MW and Visser-Meily JM. Measuring negative and positive caregiving experiences: a psychometric analysis of the Caregiver Strain Index Expanded. Clin Rehabil 2015; 29: 1224-1233.

3. Kruithof WJ, Post MW, Van Mierlo ML, et al. Caregiver burden and emotional problems in partners of stroke patients at two months and one year post-stroke: determinants and prediction. Patient Educ Couns 2016; 99: 1632-1640.

4. Smeets SM, Van Heugten CM, Geboers JF, et al. Respite care after acquired brain injury: the well-being of caregivers and patients. Arch Phys Med Rehabil 2012; 93: 834-841.

5. Oudijk D, De Boer A, Woittiez I, et al. In the spotlight: informal care in the Netherlands. The Hague: The Netherlands Institute for Social Research, 2010.

6. Cameron JI, Cheung AM, Streiner DL, et al. Stroke survivors' behavioral and psychologic symptoms are associated with informal caregivers' experiences of depression. Arch Phys Med Rehabil 2006; 87: 177-183.

7. Pearlin LI and Schooler C. The structure of coping. $J$ Health Soc Behav 1978; 19: 2-21.

8. Christensen KA, Stephens MA and Townsend AL. Mastery in women's multiple roles and well-being: adult daughters providing care to impaired parents. Health Psychol 1998; 17: 163-171.

9. Boele FW, Hoeben W, Hilverda K, et al. Enhancing quality of life and mastery of informal caregivers of highgrade glioma patients: a randomized controlled trial. $J$ Neurooncol 2013; 111: 303-311.

10. Pioli MF. Global and caregiving mastery as moderators in the caregiving stress process. Aging Ment Health 2010; 14: 603-612.

11. Simpson C and Carter P. Mastery: a comparison of wife and daughter caregivers of a person with dementia. $J$ Holist Nurs 2013; 31: 113-120.

12. GCP Begeleidingscommissie. Internationaal richtsnoer voor "good clinical practice" voor het onderzoek met geneesmiddelen; vertaling naar de Nederlandse praktijk. The Hague: Nefarma, 2003.

13. Robinson BC. Validation of a Caregiver Strain Index. $J$ Gerontol 1983; 38: 344-348.

14. Van Exel NJ, Scholte op Reimer WJ, Brouwer WB, et al. Instruments for assessing the burden of informal caregiving for stroke patients in clinical practice: a comparison of CSI, CRA, SCQ and self-rated burden. Clin Rehabil 2004; 18: 203-214. 
15. Visser-Meily JM, Post MW, Riphagen II, et al. Measures used to assess burden among caregivers of stroke patients: a review. Clin Rehabil 2004; 18: 601-623.

16. Nederlandse Vereniging voor Neurologie. Richtlijn: Diagnostiek, behandeling en zorg voor patiënten met een beroerte. Utrecht: kwaliteitsinstituut voor de Gezondheidszorg CBO, 2008.

17. Brouwer WB, Van Exel NJ, Van Gorp B, et al. The CarerQoL instrument: a new instrument to measure carerelated quality of life of informal caregivers for use in economic evaluations. Qual Life Res 2006; 15: 1005-1021.

18. Hoefman RJ, Van Exel J and Brouwer WB. Measuring the impact of caregiving on informal carers: a construct validation study of the CarerQoL instrument. Health Qual Life Outcomes 2013; 11: 173.

19. Zigmond AS and Snaith RP. The hospital anxiety and depression scale. Acta Psychiatr Scand 1983; 67: 361-370.

20. Bjelland I, Dahl AA, Haug TT, et al. The validity of the Hospital Anxiety and Depression Scale. An updated literature review. J Psychosom Res 2002; 52: 69-77.
21. Spinhoven P, Ormel J, Sloekers PP, et al. A validation study of the Hospital Anxiety and Depression Scale (HADS) in different groups of Dutch subjects. Psychol Med 1997; 27: 363-370.

22. Terwee CB, Bot SD, De Boer MR, et al. Quality criteria were proposed for measurement properties of health status questionnaires. J Clin Epidemiol 2007; 60: 34-42.

23. De Vet HCW, Terwee CB, Mokkink LB, et al. Measurement in medicine: a practical guide. Cambridge: Cambridge University Press, 2011.

24. CBS. Acht procent van de Nederlanders nooit op internet, 2016, https://www.cbs.nl/nl-nl/nieuws/2016/22/achtprocent-van-de-nederlanders-nooit-op-internet

25. Kruithof WJ, Visser-Meily JM and Post MW. Positive caregiving experiences are associated with life satisfaction in spouses of stroke survivors. J Stroke Cerebrovasc Dis 2012; 21: 801-807.

26. Cameron JI, Stewart DE, Streiner DL, et al. What makes family caregivers happy during the first 2 years post stroke? Stroke 2014; 45: 1084-1089. 